\title{
Phytochemical Screening and Cytotoxicity Evaluation of Ethanolic Extract of Hypericum cordifolium (choisy) Leaves
}

\author{
Deepak Basyal ${ }^{1}$, Netra Lal Bhandari ${ }^{2 *}$ \\ ${ }^{1}$ Department of Pharmacy, Maharajgunj Medical Campus, Institute of Medicine, Tribhuvan University, \\ Kathmandu, Nepal \\ ${ }^{2}$ Department of Chemistry, Tri-Chandra Multiple Campus, Tribhuvan University, Kathmandu, Nepal \\ *CorrespondingE-mail: netra.tu.edu@gmail.com \\ (Received: Sept. 03, 2019; Revised: Dec. 24, 2019 \& Accepted: Dec. 26, 2019)
}

\begin{abstract}
Hypericum cordifolium is a medicinal plant traditionally used for the treatment of the menstrual disorder, backache, dislocation of bone, fever, diarrhea and dysentery due to the presence of potential bioactive secondary metabolites. Ethanolic extract of dried leaf powder was prepared using the Soxhlet apparatus, followed by qualitative phytochemical screening with different reagents. In-vitro cytotoxicity assay was screened by using brine shrimp bioassay and $\mathrm{LC}_{50}$ was calculated by probit analysis. Alkaloids, glycosides, amino acids, and fixed oils were present at very minute level whereas saponin, phenolics and flavonoids were present at significant level. Cytotoxicity assay of the leaf extract showed useful results $(\mathrm{p}<0.05) . \mathrm{LC}_{50}$ of $273 \mathrm{ppm}$, which was less than $1000 \mathrm{ppm}$, showing that the plant is toxic. The study revealed that the plant possessed medicinal values, that could justify the traditional medicinal practices. This research has pointed out further possibilities of works to be done on this virgin plant creating the opportunity for scientific researches to give birth of potent lead molecules.
\end{abstract}

Keywords: Hypericum cordifolium, phytochemical screening, probit analysis, $\mathrm{LC}_{50}$.

\section{Introduction}

Medicinal plants have been the important source of medicine amongst traditional tribal healers worldwide since antiquity [1]. From the earliest times, herbs have been prized for their relieving and healing abilities, and today we still curative properties of plants [2]. According to $\mathrm{WHO}, 80 \%$ of the people living in rural areas depend on medicinal herbs as the primary healthcare system and $25 \%$ of prescribed drugs are derived from plants [2,3]. Hence, drug discovery by investigating on bioactive natural products has been most significant strategy for new drug development [4].

Cancer is one of the leading causes of death in the world, and the number of individuals infected with cancer is continuing to expand [5]. It is a group of diseases caused by loss of cell cycle control and associated with abnormal, uncontrolled cell growth. It is caused by both external factors (tobacco, chemicals, radiation and infectious organisms) and internal factors (inherited-mutations, hormones, immune conditions, the mutation that occur from metabolism) [6]. Hence, it is a significant worldwide public health problem generally due to lack of widespread and comprehensive early detection method, the associated poor prognosis of a diagnosis of disease in patients [7].

Anticancer activity means reversal, suppression or prevention of carcinogenic progression by using bioactive natural and synthetic agents [8]. Treatment options of cancer are typically expensive and unavailable in developing countries [9]. In most cases, drugs used for the treatment of cancer are not effective or have an unpleasant side effect [10]. Therefore, new drug discovery and development is necessary for further treatment option to combat these diseases. 
In the present study, one of the ethnomedicinally important plants has been selected, having very few supportive scientific researches Hypericum cordifolium, for exploration of its cytotoxicity. $H$. cordifolium is an endemic plant, well-distributed from the altitude of $900 \mathrm{~m}-1700 \mathrm{~m}$ in the central development region and some part of the western development region [11]. This plant has some ethnomedical records as a remedy for the menstrual disorder, back pain, fever. This is the most attractive indication to draw our attention for this project to discover toxicity of leaves in cattle [12]. Results show that it possess some cytotoxic molecules for this action.

Being endemic, very limited international and also national publication on this plant is available. This indicates that the real potency of $H$. cordifolium has not been justified scientifically. Hence, research aimed to explore cytotoxicity of the plant. As other Hypericum species have shown their potentiality as anticancer drugs, the $H$. cordifolium could be an alternative species with much more potentiality that can meet today's need for a drug with minimum adverse effect and maximum efficacy.

\section{Materials and Methods}

\section{Plant collection and identification}

Young leaves of Hypericum cordifolium (approx. 8 $\mathrm{kg}$ ) were collected from wild, slopy areas of Ashapuri village of Bhaktapur district in August. The plant was identified in the Pharmacognosy laboratory of the Pharmacy Department, Maharajgunj Medical Campus, Tribhuvan University, Kathmandu, Nepal.

\section{Processing of crude drug}

The leaves were stripped from the plant by carefully discarding the damaged ones. Then the leaves were thoroughly washed with water to remove the impurities and again washed with $1 \%$ saline solution. Water was strained from the leaves in the perforated bucket transferred in trays for room drying.

Leaves were thinly spread in the mosquito net in a wellventilated room. This room was an insect, rodent, and dust proof. Air circulation was maintained through room ventilations, but the direct air towards the leaves was avoided, as it could increase the contamination with germs in the air. It was dried for 15 days followed by milling using a mixture grinder. The milled leaves were sieved with the sieve of mesh size $2 \mathrm{~mm}$ to get uniform powder. It was dried at $50{ }^{\circ} \mathrm{C}$ for 30 minutes to reduce moisture content considerably below $7.5 \%$ and was stored.

\section{Solvent extraction}

The obtained powder was subjected to pre-soxhlet maceration for 6 hours, with $90 \%$ ethanol. Then the mixture was soxhleted for 48 hours with $90 \%$ ethanol with a solvent to sample ratio of $10: 1(\mathrm{v} / \mathrm{w})$. Each extract was filtered by vacuum filtration then evaporated to near dryness using a rotary evaporator. Lastly, the percentage yield of extract was calculated and stored in container (inside the refrigerator) for further studies.

\section{Phytochemical screening}

Phytochemical screening of alkaloids, saponins, tannins, flavonoids, terpenoids, resins, phenols, protein and aminoacids, phytosterol, carbohydrate, glycosides, fixedoils, and fats were carried out for ethanolic extracts as per the standard methods $[13,14]$.

\section{Brine shrimp lethality assay (cytotoxic activity)}

Brine shrimp lethality assay was conducted as per the standard method $[15,16]$. The brine shrimp bioassay is based on the ability to kill laboratory-cultured Artemia nauplii. Brine shrimp (A. salina) belongs to phylum arthropod and class crustacean. Brine shrimp are marine invertebrates about $1 \mathrm{~mm}$ in size. The eggs of brine shrimp remain viable for years in the dry state. Brine shrimp method provides a quick and economical alternative to vertebrate testing. It determines $\mathrm{LC}_{50}$ values in $\mathrm{ug} / \mathrm{mL}$ of test samples against nauplii in the brine medium.

Two unequal halves (Larger and smaller compartment) was made with a plastic divider in a 22 x $32 \mathrm{~cm}$ rectangular dish with several holes and filled with artificial seawater ( $28 \mathrm{~g}$ sea salt/L). The smaller compartment was illuminated the light. About $15 \mathrm{mg}$ eggs of A. salina were sprinkled larger compartment. After 24 hours, phototropic nauplii were collected using a Pasteur pipette from the smaller compartment. 10 shrimps were transferred to each vial containing $2 \mathrm{~mL}$ of seawater and $0.2 \mathrm{~mL}$ of $1000,500,250$ and 
$125 \mathrm{ppm}$ concentration of the extract prepared in $1 \%$ DMSO. The control vials were treated with $1 \%$ DMSO (negative control) instead of extract. Each concentration replicates was performed in triplicates. All the vials were placed under illumination at room temp, and after 24 hours, the number of survivors was counted and the percentage of deaths was calculated. Larvae not exhibiting any internal and external movement during multiple observations were considered dead. The number of death if occurred in the control was also counted and, the data were corrected using the following formula. $\mathrm{LC}_{50}$ was calculated by plotting concentration and $\%$ mortality (Probit analysis).

Percentage deaths $=($ Dead test- Dead control) $) \times 100 \%$ 10

\section{Statistical analysis}

Cytotoxicity of ethanolic extracts was carried out in various concentrations (triplicate). Data were analysed by One-way ANOVA followed by Post-Hoc Tuckey test using SPSS version 20 (SPSS Inc, Chicago).

\section{Results and Discussion}

The extractive value of ethanol was found to be highest $(45 \%)$ when compared with water $(35 \%)$ and ether $(5 \%)$. Hence the selection of ethanol as a solvent for extraction will give the highest yield i.e. a large number of compounds. The lowest extractive value of ether indicated that there is the fewer amount of non-polar constituents but the highest extractive value of ethanol, indicated a higher amount of polar constituents in leaves powder and also ethanol has the ability to extract many non-polar constituents. Water could be a choice of solvent for economic and easy extraction but there is the chance of microbial contamination on storage and extraction of only polar constituents. Hence, ethanol due to its high extraction ability and less chance of contamination, it will be the best option in solvent selection.

Table 1: Phytochemical screening of ethanolic extract of plant leaves

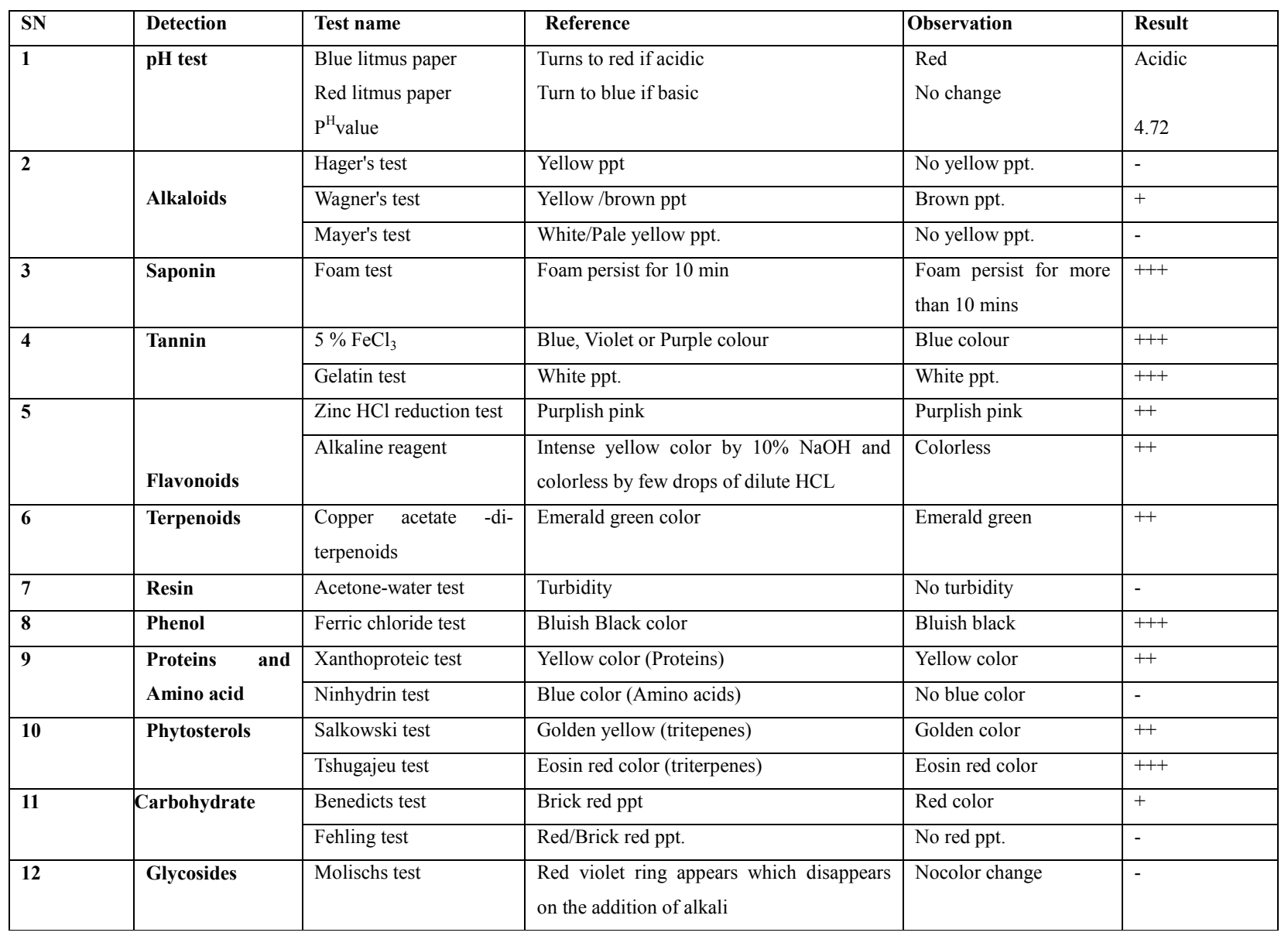


The alkaloid was present in trace amount with the positive result only in Wagner's test, but there was a negative result for other two; Hager's and Mayer's test. The various study performed in other species of Hypericum claimed xanthone only alkaloid at very minute level [17] and flavonoid and phenol as the major constituent components [18]. The screening indicated the presence of flavonoid and phenol in major amount. The test indicated a huge amount of saponin and researches showed that saponins are important therapeutically as they are shown to have hypolipidemic and anticancer activity. There was an appreciable amount of terpenoid in the extract. However, in contrast to available study which shows the appreciable amount of anthrone derivatives as hypericin, pseudohypericin, etc. in other species [19], It was found only in a minute or trace amount. Such a result might be because of a very less amount of glycosides due to loss on storage or drying or the available test might not be suitable. There was an absence of resin but the presence of a very trace amount of fixed oil. The carbohydrate gave positive results only for the Benedict's test but negative for Fehling's and Molisch test. Similarly, amino acid also exhibits dual result giving a positive result for xanthotropic whereas negative for the ninhydrin test. These dual findings might be due to inherent color leaf extract that led to confusion in observations and limited sensitivity of the test methods utilized [20].

\section{Brine shrimp cytotoxicity assay}

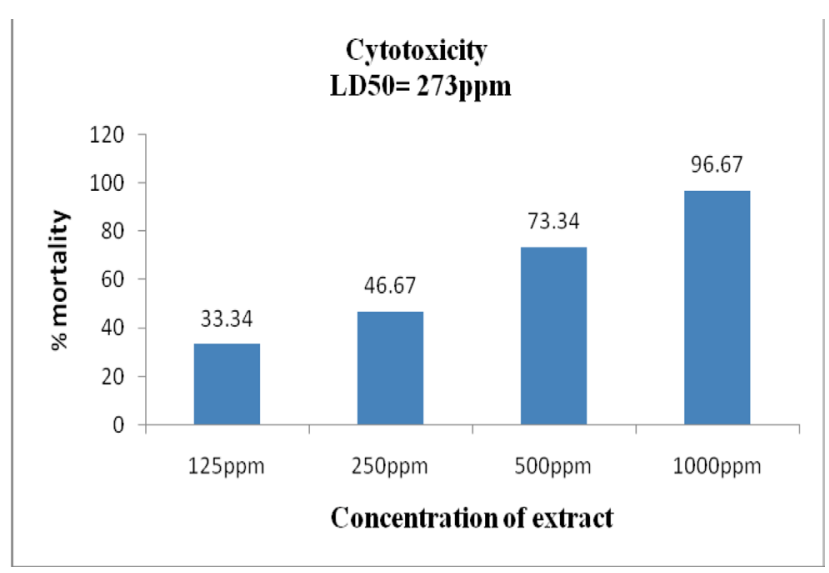

Figure 1: Brine shrimp cytotoxicity of different concerntation extract

Cytotoxicity of the extract in various concentrations was examined by Brine shrimp cytotoxicity assay and results expressed in $\mathrm{LC}_{50}$ as presented in the above figure. In the present study, the lowest concentration of $125 \mathrm{ppm}$ has also shown some range cytotoxic activity causing $33.34 \%$ mortality, whereas the highest concentration of $1000 \mathrm{ppm}$ results highest toxicity of $96.67 \%$ mortality. The $\mathrm{LC}_{50}$ from the table was obtained on the concentration of $273 \mathrm{ppm}$, which was less than $1000 \mathrm{ppm}$ that verified that the plant is toxic. From the One-Way ANOVA followed by the Post-Hoc Tuckey test, it was found that there was a significant difference between different concentrations and activity at the significant level of 0.05 .

No specific molecule from this plant has been identified but hypericin-c from $H$. riparium shows potent cytotoxic activity in brine shrimp lethality bioassay and hyperuralone A from $H$. uralum exhibited cytotoxic activity against five human cancer cell line in-vitro with $\mathrm{IC}_{50}$ of 4.6-14.4 $\mu \mathrm{M}$. As brine shrimp cytotoxic assay has been considered as a pre-screening assay for antimicrobial, antitumor, antimalarial, antifungal, and insecticidal activities and a positive correlation exist between brine shrimp lethality and human carcinoma [21-23], hence efforts have been made to determine the preliminary in-vitro anticancer activity of the extract.

\section{Conclusion}

This study concludes that ethanolic extract of this plant possessed medicinal values, that could justify the ethnomedicinal importance. Likewise, this research results have pointed out further possibilities of works on this virgin plant creating an opportunity for scientific researches to give birth of potent lead molecules as a remedy of cancer and a gift for the welfare of humanity. There is a need for further studies in this plant to clarify the in-vivo potential of this plant in the management of cancer. That was a subject of investigation in our group. Fractionation of the extract to identify bioactive fractions and further isolation and characterization of compounds are in progress.

\section{Acknowledgment}

The authors are thankful to Department of Pharmacy, Maharajgunj Medical Campus, Institute of Medicine, Tribhuvan University, Kathmandu, Nepal for providing the facilities for carrying out this research work. 


\section{References}

1. M. S. Butler, The role of natural product chemistry in drug discovery, Journal of Natural Products, 2004, 67(12), 2141-2153. (DOI: 10.1021/np040106y).

2. A. S. Rajesh, N. S. Kiran, P. C. Tripathi and K. Verma, In vitro cytotoxicity of Moringa oleifera against different human cancer cell lines, Asian Journal of Pharmaceutical and Clinical Research, 2012, 5(4), 271-2.

3. R. Dipasquale, The aboca museum: Displaying the histroy of herbal medicine in Italy and Europe, The Journal of American Botanical Council, 2005, 65, 50-57.

4. S. P. Rout, K. A. Choudary, D. M. Kar, L. O. Das and A. Jain, Plants in traditional medicinal system-future source of new drugs, International Journal of Pharmacy and Pharmaceutical Sciences, 2009, 1(1), 1-23.

5. R. S. Kumar, B. Rajkapoor and P. Perumal, Antitumor and cytotoxic activities of methanol extract of Indigofera linnaei Ali., Asian Pacific Journal of Cancer Prevention, 2011, 12(3), 613-8.

6. S. Chanda and K. Nagani, In vitro and in vivo methods for anticancer activity evaluation and some Indian medicinal plants possessing anticancer properties: an overview, Journal of Pharmacognosy and Phytochemistry, 2013, 2(2).

7. M. H. Teiten, F. Gaascht, M. Dicato and M. Diederich, Anticancer bioactivity of compounds from medicinal plants used in European medieval traditions, Biochemical Pharmacology, 2013, 86(9), 1239-1247. (DOI: 10.1016/j. bcp.2013.08.007).

8. J. Alzeer, B. R. Vummidi, R. Arafeh, W. Rimawi, H. Saleem and N. W. Luedtke, The influence of extraction solvents on the anticancer activities of Palestinian medicinal plants, Journal of Medicinal Plants Research, 2014, 8(9), 408415. (DOI: 10.5897/JMPR2013.5044).

9. A. Eghdami, H. Piri, M. Sirati-Sabet and D.
Ilghari, Investigation of anti proliferative properties and antioxidant activity of aerial parts ethanolic extract of Hypericum perforatum $L$. by breast cancer 4T1 cell lines, International Journal of Biosciences, 2013, 3(12), 265-72. (DOI: 10.12692/ijb/3.12.265-272).

10. P. S. Coker, J. Radecke, C. Guy and N. D. Camper, Potato disc tumor induction assay: a multiple mode of drug action assay, Phytomedicine, 2003, 10(2-3),133-138. (DOI: $10.1078 / 094471103321659834)$

11. N. P. Manandhar, Plants and People of Nepal, Timber Press, 2002.

12. P. K. Mukherjee, R. Verpoorte and B. Suresh, Evaluation of in-vivo wound healing activity of Hypericum patulum (Family: Hypericaceae) leaf extract on different wound model in rats, Journal of Ethnopharmacology, 2000, 70(3), 315-321. (DOI: 10.1016/S0378-8741(99)00172$5)$.

13. P. Tiwari, B. Kumar, M. Kaur, G. Kaur and H. Kaur, Phytochemical screening and, extraction: a review, Internationale Pharmaceutica Sciencia, 2011,1(1), 98-106.

14. A. Pandey and S. Tripathi, Concept of standardization, extraction and pre phytochemical screening strategies for herbal drug, Journal of Pharmacognosy and Phytochemistry, 2014, 2(5).

15. S. B. Gaikwad, M. G. Krishna, and S. J. Anerthe, Antimitotic activity and brine shrimp lethality test of Tectona grandis Linn. bark, Research Journal of Pharmaceutical, Biological and Chemical Science, 2011, 2(4), 1014-1022.

16. A. P. Peron, R. G. Mariucci, I. V. de Almeida, E. Düsman, M. S. Mantovani and V. E. Vicentini, Evaluation of the cytotoxicity, mutagenicity and antimutagenicity of a natural antidepressant, Hypericum perforatum L. (St. John's wort), on vegetal and animal test systems, $B M C$ Complementary and Alternative Medicine, 2013, 13(1), 97. (DOI: 10.1016/S02786915(01)00053-9). 
17. I. A. Nawchoo, In vitro antibacterial activity and phytochemical studies of methanolic extract of leaves of Hypericum perforatum L. growing wild in Kashmir Himalaya, Asian Journal of Plant Science and Research, 2012, 2(4), 414420. (ISSN : 2249-7412).

18. G. Çelen, S. Özkan, and F. Ayhan, The phenolic compounds from Hypericum perforatum and their antimicrobial activities, Hacettepe Journal Of Biology And Chemistry, 2008, 36(4), 339345. (DOI: 10.1055/s-2002-20053).

19. U. M. Vattikuti and V. Ciddi, An overview on Hypericum perforatum Linn., Natural Product Radiance, 2005, 4(5), 368-381.

20. K. S. Vidyalakshmi, D. A. Chales and H. R. Vasanthi, Anti-mitotic and cytotoxic effect of Mussaenda queensirkit, Journal of Pharmacology and Toxicology, 2007, 2(7), 6605. (DOI: 10.3923/jpt.2007.660.665).
21. A. V. Krishnaraju, T. V. Rao, D. Sundararaju, M. Vanisree, H. S. Tsay and G. V. Subbaraju, Assessment of bioactivity of Indian medicinal plants using brine shrimp (Artemia salina) lethality assay, International Journal of Applied Science and Engineering, 2005, 3(2), 125-134. (DOI: 10.1.1.613.7777).

22. B. Jaki, J. Orjala, H. R. Bürgi and O. Sticher, Biological screening of cyanobacteria for antimicrobial and molluscicidal activity, brine shrimp lethality and cytotoxicity, Pharmaceutical Biology, 1999, 37(2), 138-143. (DOI: 10.1076/phbi.37.2.138.6092).

23. R. Padmaja, P. C. Arun, D. Prashanth, M. Deepak, A. Amit and M. Anjana, Brine shrimp lethality bioassay of selected Indian medicinal plants, Fitoterapia, 2002, 73(6), 508-510. (DOI: 10.1016/S0367-326X(02)00182-X). 